\title{
Immunohistochemical Detection of Hypochlorite-Modified Proteins in Glomeruli of Human Membranous Glomerulonephritis
}

\author{
Hermann-Josef Gröne, Elisabeth F. Gröne, and Ernst Malle \\ German Cancer Research Center (DKFZ), Department of Cellular and Molecular Pathology (H-JG, EFG), Heidelberg, \\ Germany; and Institute of Medical Biochemistry and Medical Molecular Biology (EM), Karl-Franzens University Graz, \\ Graz, Austria
}

\begin{abstract}
SUMMARY: A proposed analogy between atherosclerosis and glomerulosclerosis suggests that factors that contribute to the development of atherosclerosis, ie, oxidatively modified (lipo)proteins, may also participate in glomerular injury. Although the nature of the in vivo oxidants has not been clearly identified, increasing evidence suggested the myeloperoxidase $(\mathrm{MPO})-\mathrm{H}_{2} \mathrm{O}_{2}-$ halide system to be responsible for the damage observed in leukocyte-dependent glomerulonephritis. MPO, a heme protein secreted by activated phagocytes, may generate modified/oxidized proteins in vivo via intermediate formation of hypochlorous acid $(\mathrm{HOCl}) / h y p o c h l o r i t e . ~ H O C l$, a reactive oxygen species and powerful oxidant, can convert (lipo)proteins into atherogenic forms in vitro and in vivo. Here we demonstrate the presence of $\mathrm{HOCl}$-modified proteins in glomeruli of patients with membranous glomerulonephritis using monoclonal antibodies that do not cross-react with other oxidative modifications. Immunostaining for $\mathrm{HOCl}$-modified epitopes in human minimal change glomerulopathy revealed glomeruli that were unreactive, although the number of MPO-positive cells/glomerulus was slightly increased in comparison to controls. In contrast to minimal change glomerulopathy, a pronounced infiltration of mononuclear cells/glomerulus in membranoproliferative glomerulonephritis is in line with pronounced staining for $\mathrm{HOCl}$-modified epitopes. Immunostaining was detected in intracapillary cells and immune complex deposits within the glomerular basement membrane. In human membranous glomerulonephritis (Stages I to III), staining for HOCl-modified proteins was localized at the basement membrane and podocytes. Staining of serial sections revealed colocalization of $\mathrm{HOCl}$-modified epitopes and MPO in glomerular peripheral basement membranes. Subsequently, tubulointerstitial staining for $\mathrm{HOCl}$-modified epitopes was observed in foam cells at the border of the cytoplasm and in damaged tubular epithelia in focal advanced chronic lesions. Our results indicate that oxidative modification of the basement membrane structure by phagocytederived $\mathrm{HOCl}$ may be of importance for glomerular defects. The observed colocalization of $\mathrm{HOCl}$-modified proteins and MPO in podocytes and adjacent basement membranes strengthens the assumption that the MPO- $\mathrm{H}_{2} \mathrm{O}_{2}$-halide system contributes to glomerular dysfunction in patients with membranous glomerulonephritis. (Lab Invest 2002, 82:5-14).
\end{abstract}

$M$ embranous glomerulonephritis (MGN) is an immune-complex glomerulonephritis characterized morphologically by subepithelial antigen deposits and clinically by significant glomerular proteinuria with nephrotic syndrome. Antigens causing this immune complex disease may be viral (eg, hepatitis $B$ virus), drug-related (eg, gold salts), or tumorassociated (Ehrenreich and Churg, 1968). In comparison to other glomerulonephritides, the number of glomerular and inflammatory cells infiltrating the glomerular convolute do not seem to increase appreciably. The antigen-antibody complexes lead to activation of the complement system (Couser, 1990), and

Received July 6, 2001.

This investigation received support from the Deutsche Forschungsgemeinschaft (project GR 728/7 to H-JG), the Kamillo Eisner Foundation, and the Austrian Research Foundation (FWF P 14186 MED and P15404-MED to $E M)$.

Address reprint requests to: Dr. Hermann-Josef Gröne, German Cancer Research Center (DKFZ), Department of Cellular and Molecular Pathology, Im Neuenheimer Feld 280, D - 69120 Heidelberg, Germany. E-mail: h.j.groene@dkfz-heidelberg.de the membrane attack complex C5a-9 has been documented in glomerular basement membranes (GBMs) (Schulze et al, 1989).

The molecular mechanisms that may instigate a loss of membrane permselectivity have partly become unraveled in passive Heymann nephritis (PHN), an established rat model of human MGN. Subepithelial deposition of immune complexes in the GBM caused complement activation and the synthesis of reactive oxygen species (ROS) (Heymann et al, 1965; Kerjaschki et al, 1989; Shah, 1988). The expression of cytochrome b558, a component of the membranebound NADPH-oxidase complex (responsible for ROS generation), is significantly increased in podocytes (Neale et al, 1993). Adducts of the lipid peroxidation products malondialdehyde (MDA)- and 4-hydroxynonenal were detected in the noncollagenous domain of type IV collagen of the GBM (Neale et al, 1994). Because type IV collagen is the major structural protein of the GBM, its oxidative modification may alter pore width and electrical charge of the GBM; loss of permselectivity and proteinuria may ensue. Pretreatment of $\mathrm{PHN}$ rats with oxygen scavengers did not 

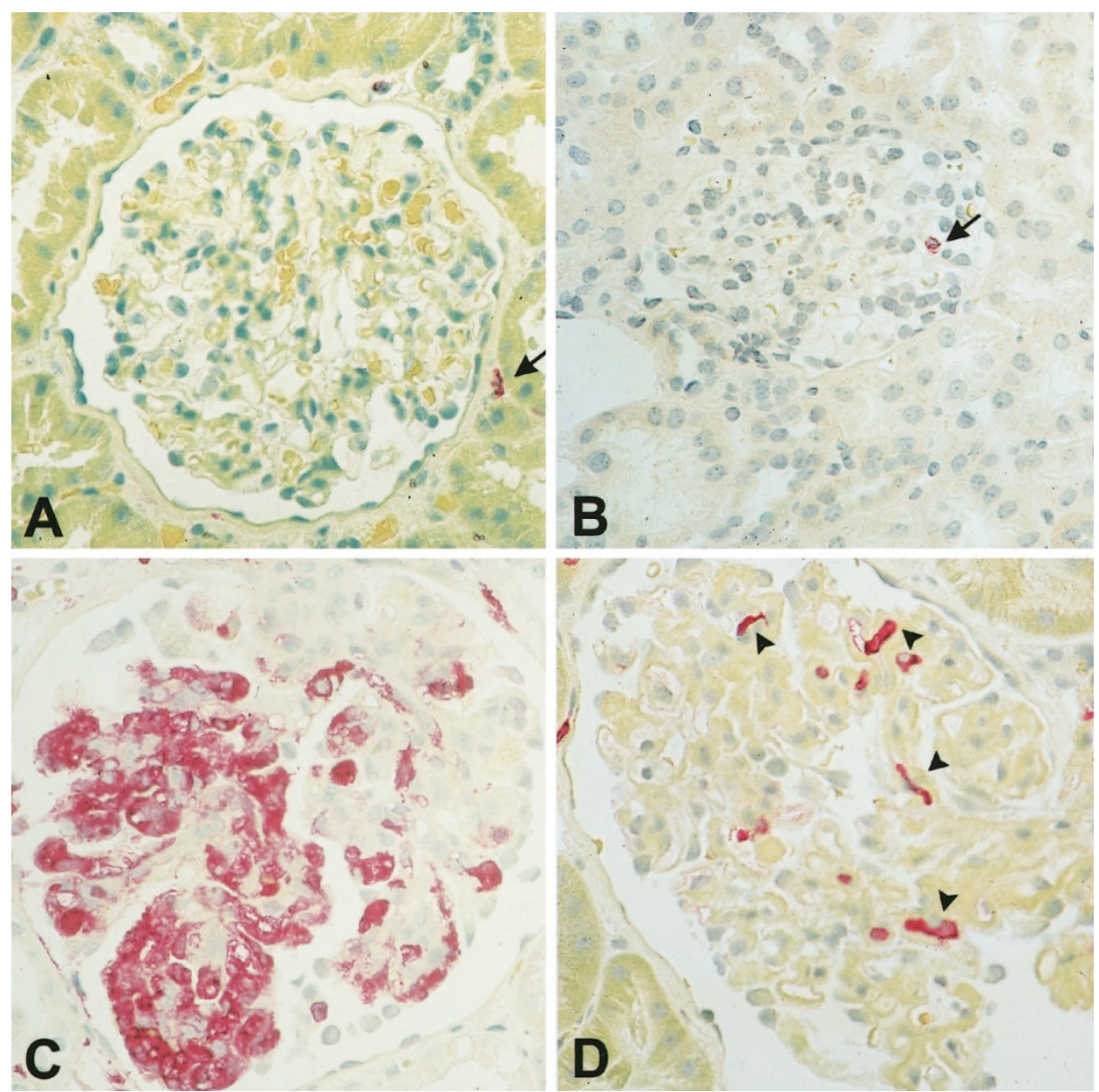

Figure 1.

Immunohistologic detection of monocyte/macrophages and myeloperoxidase (MP0)-positive cells present in glomeruli of regular kidney (controls), minimal change glomerulopathy (MCGP), membranoproliferative glomerulonephritis (MPGN), and membranous glomerulonephritis (MGN). Tissue sections were incubated with mouse anti-human myeloid/histiocyte antigen L1 or calprotectin (A to D) and rabbit polyclonal anti-human MPO IgG as primary antibodies (E to H). For detailed incubation conditions see "Materials and Methods." Staining was performed by the anti-alkaline phosphatase techniques (APAAP) method. Representative sections of tissues of Table 3 are shown. A, Staining of monocyte/macrophages in glomerulus of controls; no positive staining in glomerulus but in periglomerular capillary (arrow). B, Singular L1-antigen-positive cell in capillary of the glomerulus (arrow) of MCGP. C, Many L1-antigen-positive cells in capillaries and mesangium in MPGN; pronounced overlapping stain in left part of glomerulus. D, Few L1-antigen-positive cells in the glomerulus (arrowheads) of MGN. E, MCGP without MPO positivity in glomerulus. F, Several MPO-positive cells in glomerular convolute of MPGN. G and H, Staining for MPO in MGN; mononuclear cells within capillaries (arrows) and glomerular basement membranes (GBM) (arrowheads): G, overview of glomerulus; H, detail.

reduce formation of immune deposits (Neale et al, 1994; Shah, 1988), although proteinuria was reduced. This strengthens the hypothesis that glomerular dysfunction is mediated by ROS derived from leukocytes and residential glomerular cells (Yoshioka and Ichikawa, 1989).

Besides ROS, oxidatively modified (lipo)proteins are contributing factors to inflammatory diseases. In particular, oxidized low-density lipoprotein (ox-LDL) that is present in glomeruli (Lee and Kim, 1998) may contribute to glomerular injury in a similar manner as shown during development of atherosclerosis. Binding and uptake of ox-LDL by human mesangial cells has been reported (Coritsidis et al, 1991). However, native (lipo)proteins may also be internalized (Gröne et al, 1990), undergoing modification via intermediate formation of ROS derived from podocytes and mesangial cells (Keane et al, 1993). Recently, apolipoproteins $B$ and $E$ have also been detected within the subepithelial immune deposits of PHN (Exner et al, 1996). However, apolipoproteins from glomeruli of PHN rats showed degradation and oxidative adduct formation similar to apolipoproteins from oxidized lipoproteins in atherosclerotic lesions, suggesting lipid-peroxidation derived from reactive compounds (Exner et al, 1996).

The initial pathway for oxidant generation involves a membrane-associated NADPH oxidase that reduces oxygen to superoxide anion, which then dismutates to form $\mathrm{H}_{2} \mathrm{O}_{2} \cdot \mathrm{H}_{2} \mathrm{O}_{2}$ and/or its metabolites seem to be important ROS in polymorphonuclear cell-dependent glomerulonephritis (Rehan et al, 1985). The mechanisms of $\mathrm{H}_{2} \mathrm{O}_{2}$ nephrotoxicity apparently involve the myeloperoxidase (MPO)- $\mathrm{H}_{2} \mathrm{O}_{2}$-chloride system (Johnson et al, 1987). MPO (E.C. 1.11.1.7), a secreted heme protein (for review see Kettle and Winterbourn, 1997), amplifies the toxic potential of $\mathrm{H}_{2} \mathrm{O}_{2}$ by producing hypochlorous acid $(\mathrm{HOCl}) /$ hypochlorite in the pres- 


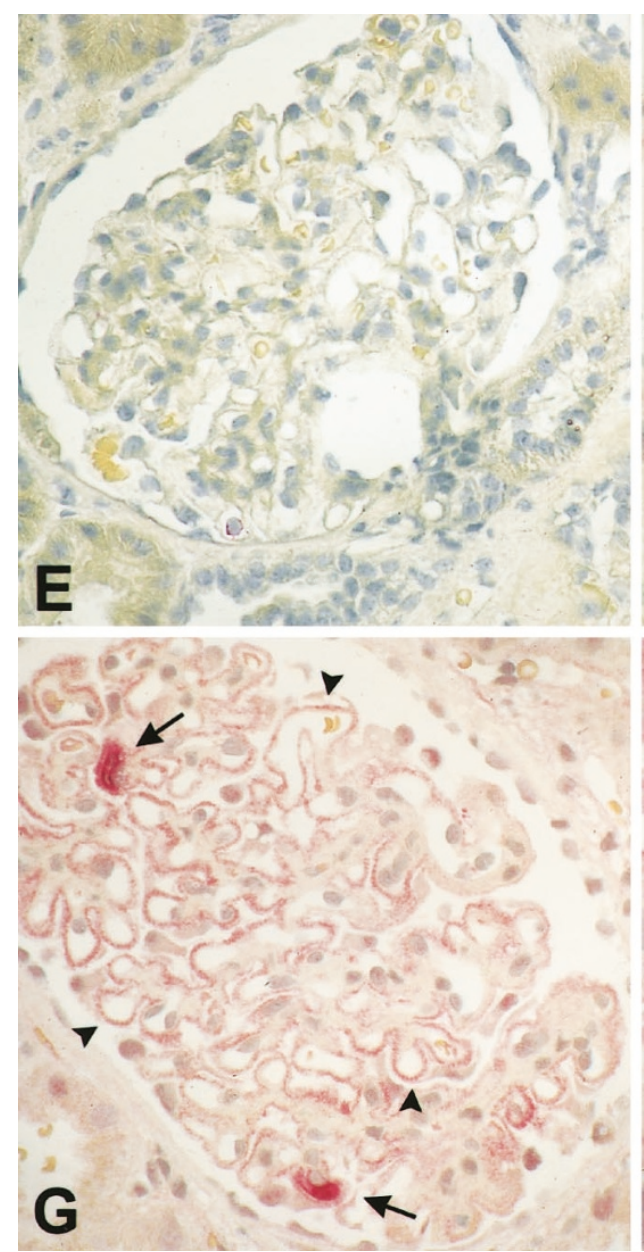

ence of chloride ions. $\mathrm{HOCl}$ itself may disrupt adhesive properties of the subendothelial matrix (Vissers and Thomas, 1997) and in turn may react with a wide range of target molecules, including lipids and proteins (Winterbourn, 1985), to form $\mathrm{N}-\mathrm{Cl}$ derivatives-compounds that in turn may exert oxidizing properties (Thomas et al, 1986). In the kidney the MPO- $\mathrm{H}_{2} \mathrm{O}_{2}-$ halide system leads to halogenation of the GBM, a process apparently caused by neutrophil adherence and subsequent generation of ROS, including $\mathrm{HOCl}$ (Vissers et al, 1985; Yoshioka and Ichikawa, 1989). The predominant in vivo sources for MPO released during the oxidative burst are neutrophils and monocytes, in which MPO makes up to $5 \%$ and $1 \%$ of the total cell protein content, respectively. Therefore, MPO is often used as a marker enzyme for measuring leukocyte accumulation in tissue samples after acute inflammatory reaction.

The importance of MPO as a potential in vivo oxidant is underlined by the presence of enzymatically active MPO in human lesion material (Daugherty et al, 1994). Most importantly, and of strong support for the involvement of the MPO- $\mathrm{H}_{2} \mathrm{O}_{2}$-chloride system in the development of atherosclerotic lesions, specific oxidation markers were identified. Both mass spectrometry analysis (Hazen and Heinecke, 1997) and immunohistochemical studies (Hazell et al, 1996; Malle et al, 2000) demonstrate that $\mathrm{HOCl}$-generated protein oxi-

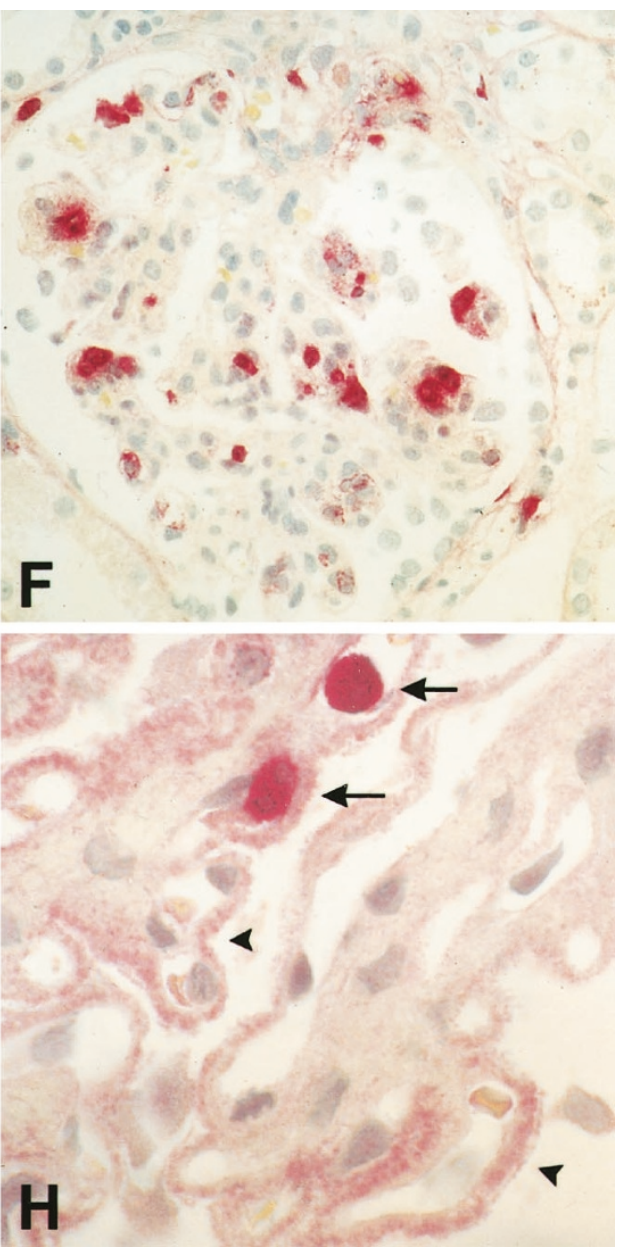

dation products are present in human atherosclerotic lesions.

Because the MPO- $\mathrm{H}_{2} \mathrm{O}_{2}$-halide system is involved in inflammatory conditions, the aim of this study was to identify MPO and $\mathrm{HOCl}$-modified proteins in glomeruli and GBMs in human MGN. The monoclonal antibodies (mAbs) used specifically recognized $\mathrm{HOCl}-$ modified (lipo)proteins and were not cross-reactive with other oxidative modifications. We herein report immunohistochemical colocalization of MPO and $\mathrm{HOCl}$-modified epitopes in human podocytes and adjacent basement membranes. Our results indicate that an oxidative modification of the basement membrane structure by $\mathrm{HOCl}$-generated only by the MPO- $\mathrm{H}_{2} \mathrm{O}_{2}$-halide system-may be of importance for glomerular defects in general, particularly in human MGN.

\section{Results}

Renal tissues from controls and diseased patients embedded in paraffin were examined for the presence of monocytes/macrophages and MPO-positive cells and for the presence of immunoreactive $\mathrm{HOCl}-$ modified epitopes. The results of biopsies are depicted in Figures 1 and 2 and Tables 1 and 2. The histologic findings in Figures 1 and 2 are representative of all the kidney specimens examined. 

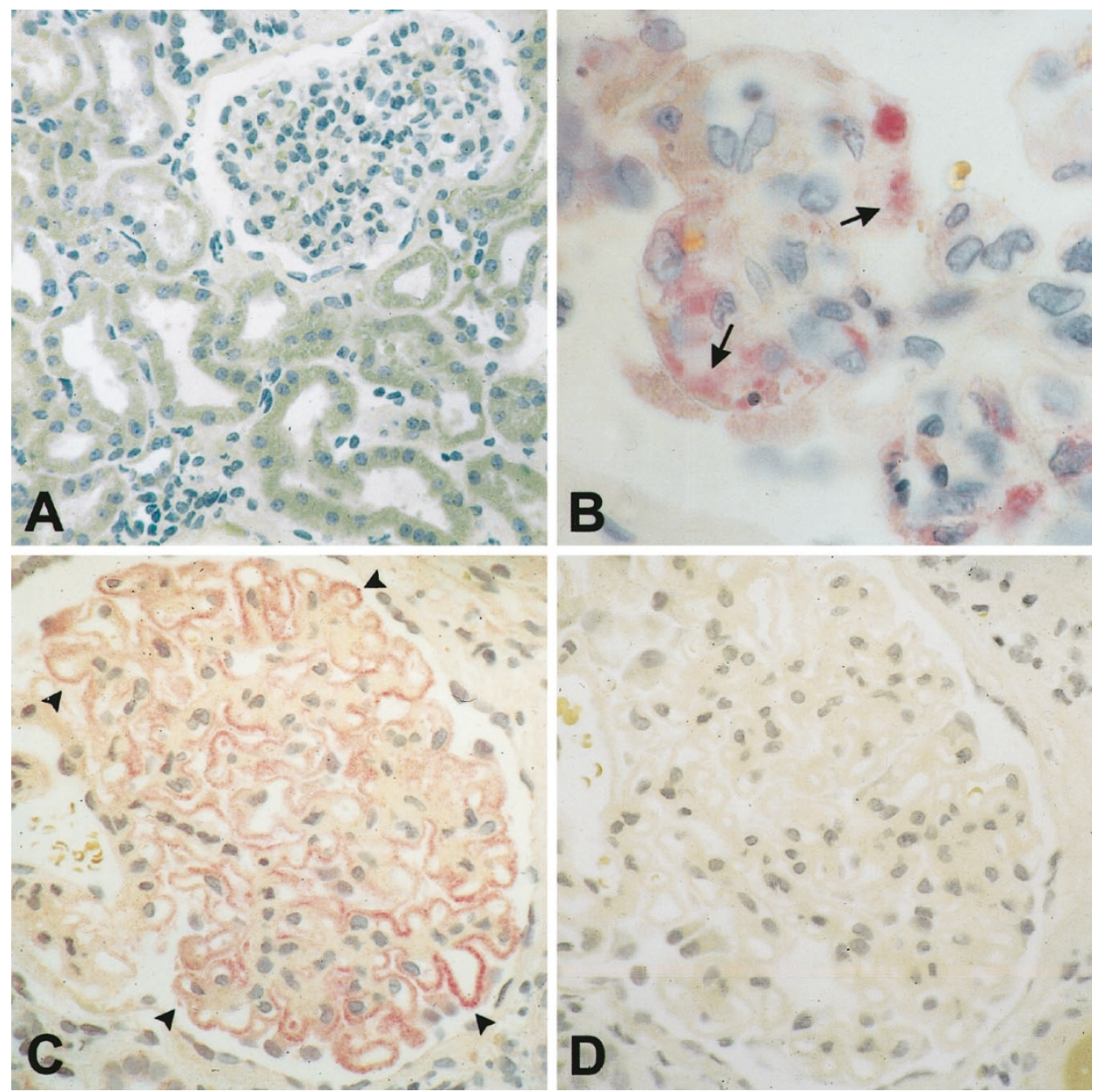

\section{Figure 2.}

Immunohistologic detection of hypochlorous acid (HOCl)-modified proteins and MPO in glomeruli of regular kidney (controls), MCGP, MPGN, and MGN. Tissue sections were incubated with monoclonal (mAb) 10A7H9 (A to D) or 6E10E11 (E to J) as primary antibodies (for detailed incubation conditions see "Materials and Methods"). Staining was performed by the APAAP method (A to H) or the immunogold-silver enhancement (IGSE) method (I and J). Representative sections from Table 3 are shown. A, Regular glomerulus from healthy controls. B, MPGN with part of glomerulus; staining for HOCl epitopes in capillaries and basement membranes (arrows). C to H, MGN (Stages I to III) with different extent and location of HOCl-modified epitopes: C, overview of glomerulus (Stage II MGN) with staining in the membrane (arrowheads); D, a parallel section to that shown in C, where the primary antibody was preabsorbed with a molar excess (100:1) of HOCl-bovine serum albumin (BSA); E, part of glomerulus (Stage II MGN) demonstrating staining for MPO in basement membranes (arrowheads) and in podocytes (arrows); $F$, a parallel section to that shown in E without primary antibody; G and H, MGN (Stage III G, Stage II H; see C for overview) with intramembranous granular label (arrowheads) for HOCl-modified epitopes corresponding to immune deposits and MPO label in Figure 1E. I, Tubulointerstitial staining in focally advanced chronic tubulointerstitial lesions showing positive flattened epithelia in ectactic tubules (arrows) and mononuclear cells (arrowheads) in MGN. J, Interstitial foam cells with pronounced staining at border of cytoplasm in MGN.

Table 1. Monocytes/Macrophages and MPO-Positive Cells in Glomeruli of Controls and Patients

\begin{tabular}{|c|c|c|c|c|}
\hline & & $\begin{array}{c}\text { Number of } \\
\text { glomeruli/biopsy }\end{array}$ & A & B \\
\hline Controls & 3 & $9.8 \pm 2.0$ & $1.7 \pm 0.4$ & $0.9 \pm 0.4$ \\
\hline MCGP & 6 & $9.5 \pm 1.5$ & $2.4 \pm 0.5$ & $1.1 \pm 0.3$ \\
\hline MPGN & 5 & $10.5 \pm 1.3$ & $33.0 \pm 10.6^{*}$ & $13.0 \pm 2.5^{*}$ \\
\hline MGN 3 & 30 & $12.5 \pm 3.0$ & $4.0 \pm 0.8^{*}$ & $2.4 \pm 0.4^{*}$ \\
\hline
\end{tabular}

A, number of L1-antigen positive cells per glomerulus; B, number of MPO-positive cells per glomerulus. Values are given as mean \pm SEM.

${ }^{\star} p<0.05$ to controls.

The number of glomeruli/biopsy specimen did not significantly differ between controls and diseased tissues from minimal change glomerulopathy (MCGP), membranoproliferative glomerulonephritis
Table 2. Staining for HOCl-Modified Epitopes in Different Stages of MGN Using mAb 6E10E11 as a Primary Antibody ${ }^{a}$

\begin{tabular}{lrrrrr}
\hline \multirow{2}{*}{$\begin{array}{c}\text { Intensity of } \\
\text { staining }\end{array}$} & & \multicolumn{5}{c}{ Stage } \\
\cline { 3 - 6 } & $\mathrm{n}$ & $\mathrm{I}$ & $\mathrm{II}$ & $\mathrm{III}$ & IV \\
\hline Slight, & 8 & 4 & 2 & 2 & 0 \\
$\quad$ segmental & & & & & \\
Moderate & 14 & 0 & 10 & 4 & 0 \\
Pronounced & 8 & 2 & 4 & 2 & 0 \\
\hline
\end{tabular}

${ }^{a}$ Classification of stages I to IV is given according to Ehrenreich and Churg (1968). The same staining pattern was obtained when mAb 10A7H9 was used as primary antibody.

${ }^{b}$ No case with stage IV was evaluated. Thus $22(73 \%)$ of 30 patients showed a significant positivity for hypochlorite-modified protein staining in the glomerulus, this compared with $100 \%$ of biopsy specimens in MPGN and $0 \%$ in MCGP and healthy controls. 

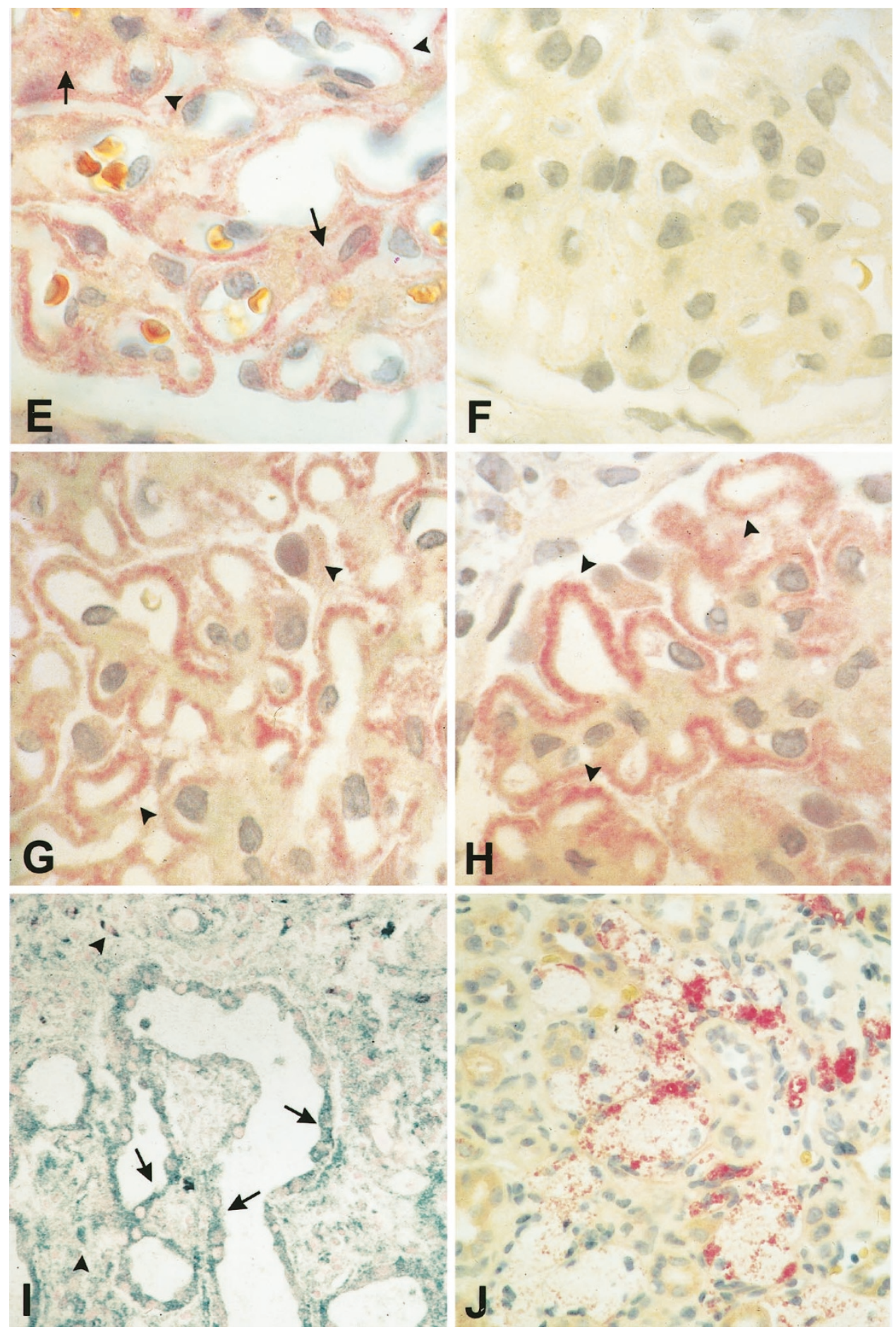

(MPGN), and MGN (Table 1). After immunohistochemistry, the number of monocytes in MCGP did not significantly differ from controls (Fig. 1, A and B). Positive staining could be observed in the periglomerular capillary as well as in capillaries of the glomerulus. However, many L1-antigen- and CD68positive cells were seen in capillaries and mesangium in MPGN (Fig. 1C). In comparison with controls, the amount of L1-antigen- and CD68-positive cells in glomeruli of MPGN was increased by approximately 20 -fold (Table 1 ). Although, by conven- tional light microscopy the number of glomerular mononuclear cells was not tremendously increased in MGN (compared with controls), a significant rise in monocytes/macrophages could be demonstrated by immunohistology in the glomerulus (Fig. 1D, Table 1).

In the next series of experiments, staining and localization of MPO in kidney biopsy specimens was performed; the identification of MPO-positive cells in glomeruli of biopsy specimens from controls and diseased kidney was comparable to that obtained with 
anti-L1-antigen or anti-CD68 IgG. In both the glomeruli of controls and MCGP, no cellular staining for immunoreactive MPO could be detected (Table 1, Fig. $1 \mathrm{E})$, whereas many MPO-positive cells were present in the glomerular convolute of MPGN biopsy specimens (Fig. 1F, Table 1). Staining for MPO in kidney biopsy specimens with MGN revealed staining of mononuclear cells within capillaries and the GBM (Fig. 1, G and $H$ ). Table 1 summarizes the number of $L 1-/ C D 68-$ and MPO-positive cells in control and diseased tissue sections. From these findings we may conclude that L1-positive cells do apparently represent the major source for MPO in MPGN.

Next we studied whether $\mathrm{HOCl}$-modified proteins are present in glomeruli of controls and patients and whether staining is associated with other cells/tissues. Immunoreactive $\mathrm{HOCl}$-modified epitopes could not be identified in either glomeruli from healthy controls (Fig. 2A) or in glomeruli from biopsy specimens with MCGP (data not shown). However, all biopsy specimens with MPGN showed irregular glomerular staining for $\mathrm{HOCl}-$ modified proteins. Staining could be observed in capillary membranes but also in the subendothelial space (Fig. 2B).

In the next series of experiments, the presence of $\mathrm{HOCl}$-modified proteins was followed in glomeruli of biopsy specimens from patients with different Stages (I to III) of MGN. In 22 (73\%) of 30 patients, a significant label could clearly be seen. In the remaining eight biopsy specimens, the $\mathrm{HOCl}$ label was segmental and weak to very weak. In kidney biopsy specimens from patients with Stage I MGN, the main area stained for $\mathrm{HOCl}$-modified proteins was the glomerulus. Staining was associated with intracapillary leukocytes and basement membranes (Fig. 2, C and H). The same staining pattern was obtained when mAb 10A7H9 was used as a primary antibody. Omission of the primary antibody (data not shown) or competition of the primary antibody with authentic HOCl-LDL ( Fig. 2D) prevented antibody binding. Also in Stage III MGN, staining for $\mathrm{HOCl}$-modified epitopes was associated with the GBM and podocytes (Fig. 2G). Omission of the primary antibody (Fig. $2 \mathrm{~F}$ ) or replacement of the corresponding $\mathrm{mAb}$ with an IgG isotype control $\left(\operatorname{lgG} 2_{b k}\right)$ eliminated all staining, demonstrating that the staining observed was a result of the mAbs rather than nonspecific effects. Also, competition with authentic $\mathrm{HOCl}-\mathrm{LDL}$ or $\mathrm{HOCl}$-bovine serum albumin (BSA) (at molar ratios of $1 / 20$ ) but not with native LDL or BSA prevented antibody binding in glomeruli at basement membranes, podocytes, and tubular epithelia (not shown), demonstrating that the staining was specific for $\mathrm{HOCl}$-modified epitopes generated in vivo by the MPO- $\mathrm{H}_{2} \mathrm{O}_{2}$-halide system.

Definitive positive staining for $\mathrm{HOCl}$ epitopes in mesangial areas was an infrequent finding (data not shown). However, it is worth mentioning that areas of the GBM positive for $\mathrm{HOCl}$-modified epitopes were often also positive when anti-human MPO IgG was used in parallel sections. These findings are indicative for the colocalization of MPO with $\mathrm{HOCl}$-modified proteins (Fig. 2, E, G, and H). In general it could be observed that the higher the mean number of monocytes/macrophages or MPO-containing cells per glomerulus, the stronger the intensity of the glomerular staining for $\mathrm{HOCl}$-modified epitopes. In biopsy specimens from Stage I MGN, staining was either very faint to slight or showed a segmentally accentuated positivity (Table 2). In biopsy specimens from Stage II and III MGN, the staining was more pronounced, showing positivity for $\mathrm{HOCl}$-modified epitopes in between moderate and intensive in the majority of patients.

Positive staining for $\mathrm{HOCl}-$ modified proteins could also be found in atrophic tubules. However, interstitial mononuclear cells and foam cells also showed staining for $\mathrm{HOCl}$-modified epitopes (Fig. 2, I and J), findings that are in accordance with our previous data in which $\mathrm{HOCl}$-modified proteins were identified in human interstitial nephritis (Malle et al, 1997).

\section{Discussion}

The results presented here show that $\mathrm{HOCl}$-modified proteins are present in glomeruli of patients with MPGN and MGN. Using specific IgG mAbs, HOClmodified epitopes generated in vivo by the MPO$\mathrm{H}_{2} \mathrm{O}_{2}$-halide system were detected by immunohistochemistry in human podocytes and intracapillary cells and extracellularly in basement membranes. In parallel, immunohistochemical localization of $\mathrm{HOCl}$ modified proteins was observed at sites at which $\mathrm{MPO}$, the only enzyme known to generate $\mathrm{HOCl}$, could be detected. Because ROS are contributing factors to kidney damage in vivo (Baud and Ardaillou, 1986), we may conclude from our findings that the MPO- $\mathrm{H}_{2} \mathrm{O}_{2}-$ halide system is relevant for glomerular dysfunction in different forms of human glomerulonephritis.

Several lines of evidence indicate that lipoproteins are among the list of factors that contribute to the development of glomerulosclerosis, perhaps mimicking some pathways leading to atherosclerosis (Diamond and Karnovsky, 1988; Gröne et al, 1994). $\mathrm{Cu}^{2+}$ ox-LDL, a convenient experimental model of physiologically important LDL modification, binds to mesangial cells (Coritsidis et al, 1991). Ox-LDL may be taken up by macrophage scavenger receptordependent pathways, leading to cholesterol engorged foam cells in the kidney. Once internalized, the modified particles may stimulate the synthesis of growth factors, cytokines, and other mediators of matrixprotein synthesis and even activate extracellular signal-regulated kinases (Ha et al, 1998; Jenkins et al, 2000; Kamanna et al, 1996; Tan et al, 1997). Indeed, ox-LDL has been identified in experimental focal glomerulonephritis in hypercholesterolemic rats in vivo (Magil et al, 1993). However, glomerular staining for IgG mAbs (raised against lysine adducts of arachidonic acid-mediated products or MDA-LDL) appeared stronger and more extensive than that for IgM mAbs, recognizing ox-LDL (Magil et al, 1993). Immunohistochemical identification of modified LDL by another IgM mAb (cross-reacting with MDA- and $\mathrm{Cu}^{2+}$-oxLDL epitopes) revealed staining in nonsclerotic glomeruli (intracellularly and extracellularly), in the scle- 
rotic segments of a glomerulus, and in foam cells of rats in which nephrosis was induced by puromycin aminonucleoside (Lee et al, 1997). Subsequently, the presence of lipid peroxidation products in kidney from PHN rats, an animal model of human MGN, gives further credence to the effect of ROS in the formation of glomerular lipid peroxidation products (Exner et al, 1996; Neale et al, 1994). In human renal tissues, immunoreactivity supposedly showing peroxidation products, ie, MDA adducts, was documented in expanded mesangial areas in early diabetic nephropathy but also in lesions of focal segmental glomerulosclerosis and mesangial areas (Horie et al, 1997; Lee and Kim, 1998).

Although we have not followed the presence of lipid peroxidation products in human MGN, the overall staining patterns observed for the presence of $\mathrm{HOCl}-$ modified epitopes were similar to those reported for ox-LDL (Horie et al, 1997; Lee and Kim, 1998; Lee et al, 1997). This suggests that (lipo)protein lipid peroxidation and $\mathrm{HOCl}$-mediated oxidation might occur in similar locations. Indeed, tyrosyl radicals, generated by MPO in vivo in the absence of chloride ions, may initiate lipid peroxidation (Savenkova et al, 1994). Subsequently, nitrogen dioxide radicals generated by the MPO- $\mathrm{H}_{2} \mathrm{O}_{2}$-nitrite system may also promote lipid peroxidation (Hazen et al, 1999), while secondary radicals derived from chloramines of proteins may also contribute to $\mathrm{HOCl}$-induced lipid peroxidation of (lipo)proteins (Hazell et al, 1999). In support for this is the observation that enhanced generation of ROS in hyperlipidemia-induced renal damage is tightly coupled with the generation of $\mathrm{HOCl}$-modified epitopes (Scheuer et al, 2000).

At the GBM, leukocytes may be stimulated by trapped immune complexes to adhere and to produce oxidants at the site of attachment (Yoshioka and Ichikawa, 1989). Both hydroxyl radicals and $\mathrm{H}_{2} \mathrm{O}_{2}$ are involved in depolymerization of GBM-heparan sulfate, leading to the loss of GBM integrity and albuminuria (Raats H et al, 1997). Neutrophil-derived MPO may be localized, presumably on a charge basis, on the GBM without causing demonstrable injury. However, subsequent exposure to $\mathrm{H}_{2} \mathrm{O}_{2}$ results in severe glomerular damage associated with halogenation of the GBM (Johnson et al, 1988). Although we did not perform immunoelectron microscopy to precisely locate binding sites of MPO within the GBM (because of paraffin embedding for routine work), the light microscopy observations suggested binding of MPO to subepithelial and intramembranous immune deposits. The epitopes generated by the MPO- $\mathrm{H}_{2} \mathrm{O}_{2}$-halide pathway are primarily protein-chloramine-adducts, which in turn may exert cytotoxicity, chemotactic and immune modulating activities, and alterations in intracellular calcium concentrations (Hammer et al, 2001; Thomas et al, 1986; Woenckhaus et al, 1998; Zabe et al, 1999). The fact that $\mathrm{HOCl}$-modified lipoproteins are preferential ligands for scavenger receptors (Marsche et al, 2001 ) is of supporting evidence that chloramine derivatives could exert profound changes in intracellular signaling pathways in the kidney as reported for ox-LDL (Jenkins et al, 2000).

The number of MPO-positive cells in MGN parallels those of monocytes/macrophages, cells that contribute to glomerular injury in PHN rats (Hara et al, 1991) and represent a source for immunoreactive MPO in tissues. The pronounced immunohistochemical staining for $\mathrm{HOCl}$-modified epitopes in glomeruli and in the cytoplasm of podocytes is indicative for ROS and ROS-induced development of glomerular capillary wall damage (Schulze et al, 1989). In PHN, in which $\mathrm{H}_{2} \mathrm{O}_{2}$ also accumulates within the glomerular capillary wall, proteinuria requires formation of the complement C5b-9 membrane attack complex, which is presumably triggered by complexes of lipid antigens associating with megalin/gp330 immune complexes (Kerjaschki et al, 1989; Neale et al, 1994). The role of podocytes seems to retrieve the membrane attack complex and subsequently to inactivate these protein complexes by endocytosis, a mechanism leading to sublytic damage.

In summary, we could show by immunohistochemistry the presence of $\mathrm{HOCl}$-modified proteins in human MPGN and in different stages of MGN. In particular, the in situ colocalization of $\mathrm{HOCl}$-modified epitopes and MPO suggests the MPO- $\mathrm{H}_{2} \mathrm{O}_{2}$-halide system to be responsible for renal hemodynamic alterations and progressive chronic renal diseases in vivo. How HOClmodified proteins are formed in human MGN in vivo could be in part by intermediate formation of lipid peroxidation products. However, the presence of $\mathrm{HOCl}$-modified proteins in human glomerulonephritis indicates that MPO, an enzyme present under inflammatory conditions, may act as a candidate for oxidative modification in the kidney.

\section{Methods}

\section{Reagents}

BSA (fatty-acid free) was obtained from Sigma (Taufkirchen, Germany). Goat anti-mouse IgG (peroxidase conjugated) was obtained from Chemicon (Temecula, California). Polyclonal antibodies (rabbit antihuman MPO IgG fraction, rabbit anti-mouse antibody, and mouse anti-rabbit antibody) and mAbs (mouse anti-human CD68 and mouse anti-human myeloid/ histiocyte antigen) were obtained from Dako (Glostrup, Denmark). Two different IgG mAbs (clone 6E10E11 and 10A7H9) raised against $\mathrm{HOCl}$-modified LDL (800 molecules of $\mathrm{HOCl}$ per LDL particle) were used (Malle et al, 2000). Characterization of the mAbs revealed them to be highly specific for $\mathrm{HOCl}$-modified epitopes and not to cross-react with other oxidative (lipo)protein modifications, ie, peroxynitrite-LDL, hemin-LDL, $\mathrm{Cu}^{2+}-\mathrm{ox}-\mathrm{LDL}$, 4-hydroxynonenal-LDL, MDA-LDL, glycated-LDL, or acetylated-LDL. The mAbs recognize a specific epitope present on various proteins after treatment with hypochlorite added as reagent or generated by the $\mathrm{MPO}-\mathrm{H}_{2} \mathrm{O}_{2}$-halide system.

For competition experiments, HOCl-LDL was prepared as described (Malle et al, 1995), and HOCl-BSA 
was obtained in a similar fashion. Briefly, $1 \mathrm{mg}$ of protein (LDL or BSA) per milliliter of phosphatebuffered saline (PBS) ( $\mathrm{pH}$ 7.4) was incubated with $\mathrm{HOCl}$ solution at $4^{\circ} \mathrm{C}$ up to 2 hours at $\mathrm{pH} 7.4$. $\mathrm{HOCl}$ was used at a ratio of 800 molecules per LDL particle and 100 molecules per BSA particle, respectively.

\section{Human Renal Tissues}

Human renal tissue consisted of transcutaneous renal biopsy specimens. Renal biopsy specimens were fixed in $4 \%(\mathrm{v} / \mathrm{v})$ phosphate-buffered formaldehyde solution (99 mM NaH ${ }_{2} \mathrm{PO}_{4}, 108 \mathrm{mM} \mathrm{Na}_{2} \mathrm{HPO}_{4}, 248$ $\mathrm{mM} \mathrm{NaCl}, \mathrm{pH} 7.35$ ) at $4^{\circ} \mathrm{C}$ for 24 hours; phosphatebuffered formaldehyde-fixed tissues were then embedded in paraffin. The specimens were primarily used to obtain a clinicopathologic diagnosis by performing (a) light microscopy stains (periodic acidSchiff and Goldner Trichrome) and (b) immunohistology for immunoglobulins $A, G$, and $M$ and complement factors $\mathrm{C} 3$ and $\mathrm{C} 1 \mathrm{q}$ and fibrinogen/fibrin on protease-treated paraffin sections by the alkaline phosphatase anti-alkaline phosphatase techniques (APAAP, see below). In addition, (c) transmission electron microscopy on araldite-embedded ultrathin sections was performed.

Details of patients and their clinicopathologic diagnoses of renal diseases, ie, (a) MCGP without focal and segmental glomerulosclerosis, (b) type I MPGN, and (c) MGN, were listed in Table 3. Control biopsy specimens that were taken because of microhematuria were regular renal parenchyma as judged by histopathologic techniques mentioned above. Approval by the ethics committee of the Medical Faculty of the University of Heidelberg was obtained to use the embedded tissue samples for further investigation.

\section{Immunohistochemistry}

Immunohistochemistry was carried out on $5-\mu \mathrm{m} \mathrm{sec-}$ tions of paraffin-embedded tissue listed in Table 3 using either the APAAP technique or immunogoldsilver enhancement (IGSE) technique.

\section{APAAP Technique}

Tissue sections were deparaffinized, rehydrated, and incubated with mAbs used at a 1:1 dilution of the corresponding hybridoma supernatant (clones 6E10E11 and 10A7H9, containing 16.5 to $46.3 \mu \mathrm{g}$ $\mathrm{lgG} / \mathrm{ml})$. For competition experiments, the primary antibody was preincubated with the competitor

Table 3. Age and Sex of Patients and Histopathologic Diagnosis of Renal Tissues Taken for Immunohistology

\begin{tabular}{lrcc}
\hline Histologic Diagnosis & $n$ & Sex (male/female) & $\mathrm{Age}^{\star}(\mathrm{yrs})$ \\
\hline Controls & 3 & $2 / 1$ & $28.0 \pm 9.1$ \\
MCGP & 6 & $4 / 2$ & $33.3 \pm 8.5$ \\
MPGN & 5 & $2 / 3$ & $49.6 \pm 5.1$ \\
MGN & 30 & $16 / 14$ & $48.1 \pm 3.1$ \\
\hline
\end{tabular}

* Mean \pm SEM.
(HOCl-LDL or HOCl-BSA) at the concentration indicated and then added to the section. After application of mAbs to the slides for 2 hours at $22^{\circ} \mathrm{C}$, a rabbit anti-mouse antibody ( $Z$ 259; Dako) was used at a dilution of $1: 40$ at $22^{\circ} \mathrm{C}$ for 1 hour; alkaline-phosphatase-conjugated mouse mAb (diluted 1:40) was then incubated at $22^{\circ} \mathrm{C}$ for 1 hour. All dilutions were done in PBS (pH 7.6). For staining, slides were exposed to a solution of sodium nitrite $(28 \mathrm{mM})$, new fuchsin (basic fuchsin) (21 mM), naphthol-AS-BI-phosphate $(0.5$ $\mathrm{mM})$, dimethylformamide $(64 \mathrm{mM})$, and levamisole (5 $\mathrm{mM})$ in $50 \mathrm{mM}$ Tris/HCl buffer $(\mathrm{pH}$ 8.4, containing 146 $\mathrm{mM} \mathrm{NaCl}$ ) for 15 minutes.

Immunohistochemical detection of MPO was done by rabbit polyclonal anti-human IgG (diluted 1:100) and the APAAP method by adding a polyclonal mouse anti-rabbit antibody (M 737, diluted 1:50; Dako) before the addition of polyclonal rabbit anti-mouse antibody (Z 259; Dako), followed by the reaction steps described above.

Characterization of cells was primarily performed on the basis of their morphology as assessed by counterstaining with aqueous hematoxylin before application of gelatin mounting medium. To further characterize monocytes/macrophages and to detect human cytoplasmic antigen (L1-antigen or calprotectin) expressed in granulocytes, blood monocytes and tissues histiocytes, serial sections were stained with either monoclonal anti-human CD68 (clone KP1, diluted 1:50; Dako) or monoclonal anti-human myeloid/ histiocyte antigen (clone MAC 387, diluted 1:50; Dako). The immunohistochemical procedure was performed as described above.

\section{IGSE Technique}

To block unspecific binding sites, tissue sections were incubated with skim milk $(4 \%, \mathrm{w} / \mathrm{v})$ in $50 \mathrm{mM}$ Tris/ $\mathrm{HCl}$ $(\mathrm{pH} 7.6$, containing $146 \mathrm{mM} \mathrm{NaCl})$ at $22^{\circ} \mathrm{C}$ for 25 minutes. After incubation of tissue sections with mAbs (clone 6E10E11 or 10A7H9) for 1 hour at $22^{\circ} \mathrm{C}$, a biotinylated goat anti-mouse antibody (Jackson ImmunoResearch Labs, West Grove, Pennsylvania), diluted 1:800 in skim milk $(2 \%, \mathrm{w} / \mathrm{v}$, in $50 \mathrm{mM}$ Tris/ $/ \mathrm{HCl}$, $\mathrm{pH}$ 7.6), was applied at $22^{\circ} \mathrm{C}$ for 30 minutes. Then a peroxidase-coupled streptavidin (diluted 1:2000 in the same buffer) was used for 30 minutes at $22^{\circ} \mathrm{C}$. Finally a polyclonal antibody against horseradish peroxidase coupled with 6-nm gold particles was added at $22^{\circ} \mathrm{C}$ for 45 minutes; the antibody was diluted 1:20 in PBS $(\mathrm{pH} 7.6)$ containing BSA $(1 \%, w / v)$, Triton $\mathrm{X}-100$ $(0.01 \%, w / v)$, and Tween $20(0.01 \%, w / v)$. After fixation of the section in PBS (pH 7.6) containing $2 \%(\mathrm{v} / \mathrm{v})$ glutaraldehyde, a silver enhancement was performed at $22^{\circ} \mathrm{C}$ for about 15 minutes, stopping the reaction depending on light microscopic appearance of staining intensity. The silver enhancement solution contained citric acid $(71 \mathrm{mM})$, tri-sodium citrate $(12 \mathrm{mM})$, hydrochinone $(22 \mathrm{mM})$, and silver acetate $(12 \mathrm{mM})$. Thereafter slides were exposed to developing solution (Kodak Readymatic R; Kodak, Rochester, New York). Kernechtrot $(1 \%$, w/v) was taken as counterstain. 
Control experiments for the immunohistochemical assays encompassed immunohistology (a) with nonimmune mouse lgG, (b) with $\mathrm{HOCl}-\mathrm{LDL}$ or HOCl-BSA as competing antigens, (c) without primary monoclonal or polyclonal antibodies, (d) without secondary antibody, or (e) without alkaline phosphatase- or immunogold-coupled antibodies.

\section{References}

Baud L and Ardaillou R (1986). Reactive oxygen species: Production and role in the kidney. Am J Physiol 251:F765776.

Coritsidis G, Rifici V, Gupta S, Rie J, Shan ZH, Neugarten J, and Schlondorff D (1991). Preferential binding of oxidized LDL to rat glomeruli in vivo and cultured mesangial cells in vitro. Kidney Int 39:858-866.

Couser WG (1990). Mediation of immune glomerular injury. J Am Soc Nephrol 1:13-29.

Daugherty A, Dunn JL, Rateri DL, and Heinecke JW (1994). Myeloperoxidase, a catalyst for lipoprotein oxidation, is expressed in human atherosclerotic lesions. J Clin Invest 94: 437-444.

Diamond JR and Karnovsky MJ (1988). Focal and segmental glomerulosclerosis: analogies to atherosclerosis. Kidney Int 33:917-924.

Ehrenreich T and Churg J (1968). Pathology of membranous nephropathy. Pathol Ann 3:145-186.

Exner M, Susani M, Witztum JL, Hovorka A, Curtiss LK, Spitzauer S, and Kerjaschki D (1996). Lipoproteins accumulate in immune deposits and are modified by lipid peroxidation in passive Heymann nephritis. Am J Pathol 149:13131320.

Gröne EF, Walli AK, Gröne HJ, Miller B, and Seidel D (1994). The role of lipids in nephrosclerosis and glomerulosclerosis. Atherosclerosis 107:1-13.

Gröne HJ, Walli AK, Gröne E, Kramer A, Clemens MR, and Seidel D (1990). Receptor mediated uptake of apo B and apo E rich lipoproteins by human glomerular epithelial cells. Kidney Int 37:1449-1459.

Ha H, Roh DD, Kirschenbaum MA, and Kamanna VS (1998). Atherogenic lipoproteins enhance mesangial cell expression of platelet-derived growth factor: Role of protein tyrosine kinase and cyclic AMP-dependent protein kinase A. J Lab Clin Med 131:456-465.

Hammer A, Desoye G, Dohr G, Sattler W, and Malle E (2001). Myeloperoxidase-dependent generation of hypochloritemodified proteins in human placental tissues during pregnancy. Lab Invest 81:543-554.

Hara M, Batsford SR, Mihatsch MJ, Bitter-Suermann D, and Vogt A (1991). Complement and monocytes are essential for provoking glomerular injury in passive Heymann nephritis in rats: Terminal complement components are not the sole mediators of proteinuria. Lab Invest 65:168-179.

Hazell LJ, Arnold L, Flowers D, Waeg G, Malle E, and Stocker $R$ (1996). Presence of hypochlorite-modified proteins in human atherosclerotic lesions. J Clin Invest 97:1535-1544.

Hazell LJ, Davies MJ, and Stocker R (1999). Secondary radicals derived from chloramines of apolipoprotein $\mathrm{B}-100$ contribute to $\mathrm{HOCl}$-induced lipid peroxidation of low-density lipoproteins. Biochem J 339:489-495.
Hazen SL and Heinecke JW (1997). 3-Chlorotyrosine, a specific marker of myeloperoxidase-catalyzed oxidation, is markedly elevated in low density lipoprotein isolated from human atherosclerotic intima. J Clin Invest 99:2075-2081.

Hazen SL, Zhang R, Shen Z, Wu W, Podrez EA, MacPherson JC, Schmitt D, Mitra SN, Mukhopadhyay C, Chen Y, Cohen PA, Hoff HF, and Abu-Soud HM (1999). Formation of nitric oxide-derived oxidants by myeloperoxidase in monocytes: pathways for monocyte-mediated protein nitration and lipid peroxidation in vivo. Circ Res 85:950-958.

Heymann W, Kmetec EP, Wilson SG, Hunter JL, Hackel DB, Okuda R, and Cuppage $F$ (1965). Experimental autoimmune renal disease in rats. Ann N Y Acad Sci 124:310-322.

Horie K, Miyata T, Maeda K, Miyata S, Sugiyama S, Sakai H, Strihou CY, Monnier VM, Witztum JL, and Kurokawa K (1997). Immunohistochemical colocalization of glycoxidation products and lipid peroxidation products in diabetic renal glomerular lesions: Implication for glycoxidative stress in the pathogenesis of diabetic nephropathy. J Clin Invest 100: 2995-3004.

Jenkins AJ, Velarde V, Klein RL, Joyce KC, Phillips KD, Mayfield RK, Lyons TJ, and Jaffa AA (2000). Native and modified LDL activate extracellular signal-regulated kinases in mesangial cells. Diabetes 49:2160-2169.

Johnson RJ, Couser WG, Chi EY, Adler S, and Klebanoff SJ (1987). New mechanisms for glomerular injury: Myeloperoxidase-hydrogen peroxide-halide system. J Clin Invest 79:1379-1387.

Johnson RJ, Guggenheim SJ, Klebanoff SJ, Ochi RF, Wass A, Baker P, Schulze M, and Couser WG (1988). Morphologic correlates of glomerular oxidant injury induced by the myeloperoxidase-hydrogen peroxide-halide system of the neutrophil. Lab Invest 58:294-301.

Kamanna VS, Pai R, Roh DD, and Kirschenbaum MA (1996). Oxidative modification of low-density lipoprotein enhances the murine mesangial cell cytokines associated with monocyte migration, differentiation, and proliferation. Lab Invest 74:1067-1079.

Keane WF, O'Donnell MP, Kasiske BL, and Kim Y (1993). Oxidative modification of low-density lipoproteins by mesangial cells. J Am Soc Nephrol 4:187-194.

Kerjaschki D, Schulze M, Binder S, Kain R, Ojha PP, Susani M, Horvat R, Baker PJ, and Couser WG (1989). Transcellular transport and membrane insertion of the C5b-9 membrane attack complex of complement by glomerular epithelial cells in experimental membranous nephropathy. J Immunol 143: $546-552$.

Kettle AJ and Winterbourn CC (1997). Myeloperoxidase: A key regulator of neutrophil oxidant production. Redox Rep 3:3-15.

Lee HS, Jeong JY, Kim BC, Kim YS, Zhang YZ, and Chung HK (1997). Dietary antioxidant inhibits lipoprotein oxidation and renal injury in experimental focal segmental glomerulosclerosis. Kidney Int 51:1151-1159.

Lee HS and Kim YS (1998). Identification of oxidized low density lipoprotein in human renal biopsies. Kidney Int 54: 848-856.

Magil AB, Frohlich JJ, Innis SM, and Steinbrecher UP (1993). Oxidized low-density lipoprotein in experimental focal glomerulosclerosis. Kidney Int 43:1243-1250. 
Malle E, Hazell L, Stocker R, Sattler W, Esterbauer H, and Waeg G (1995). Immunologic detection and measurement of hypochlorite-modified LDL with specific monoclonal antibodies. Arterioscler Thromb Vasc Biol 15:982-989.

Malle E, Waeg G, Schreiber R, Gröne E, Sattler W, and Gröne $\mathrm{HJ}$ (2000). Immunological evidence for the myeloperoxidase/ $\mathrm{H}_{2} \mathrm{O}_{2}$ /halide system in human atherosclerotic lesions: Colocalization of myeloperoxidase and hypochlorite-modified proteins. Eur J Biochem 267:4495-4503.

Malle E, Woenckhaus C, Waeg G, Esterbauer H, Gröne EF, and Gröne HJ (1997). Immunological evidence for hypochlorite-modified proteins in human kidney. Am J Pathol 150:603-615.

Marsche G, Levak-Frank S, Quehenberger O, Heller R, Sattler W, and Malle E (2001). Identification of the human analog of SR-BI and LOX-1 as receptors for hypochlorite-modified high-density lipoprotein on human umbilical venous endothelial cells. FASEB J 15:1095-1097.

Neale TJ, Ojha PP, Exner M, Poczewski H, Ruger B, Witztum $\mathrm{JL}$, Davis P, and Kerjaschki D (1994). Proteinuria in passive Heymann nephritis is associated with lipid peroxidation and formation of adducts on type IV collagen. J Clin Invest 94:1577-1584.

Neale TJ, Ullrich R, Ojha P, Poczewski H, Verhoeven AJ, and Kerjaschki D (1993). Reactive oxygen species and neutrophil respiratory burst cytochrome b558 are produced by kidney glomerular cells in passive Heymann nephritis. Proc Natl Acad Sci USA 90:3645-3649.

Raats CJ, Bakker MA, van den Born J, Berden JH (1997). Hydroxyl radicals depolymerize glomerular heparan sulfate in vitro and in experimental nephrotic syndrome. J Biol Chem 272:26734-26741.

Rehan A, Johnson KJ, Kunkel RG, Wiggins RC (1985). Role of oxygen radicals in phorbol myristate acetate-induced glomerular injury. Kidney Int 27:503-511.

Savenkova ML, Mueller DM, and Heinecke JW (1994). Tyrosyl radical generated by myeloperoxidase is a physiological catalyst for the initiation of lipid peroxidation in low density lipoprotein. J Biol Chem 269:20394-20400.

Scheuer H, Gwinner W, Hohbach J, Gröne EF, Brandes RP, Malle E, Olbricht CJ, Walli AK, and Gröne HJ (2000). Oxidant stress in hyperlipidemia-induced renal damage. Am J Physiol (Renal Physiol) 278:F63-F74.
Schulze M, Baker PJ, Perkinson DT, Johnson RJ, Ochi RF, Stahl RA, and Couser WG (1989). Increased urinary excretion of $\mathrm{C} 5 \mathrm{~b}-9$ distinguishes passive Heymann nephritis in the rat. Kidney Int 35:60-68.

Shah SV (1988). Evidence suggesting a role for hydroxyl radical in passive Heymann nephritis in rats. Am $\mathrm{J}$ Physiol 254:F337-F344.

Tan MS, Lee YJ, Shin SJ, and Tsai JH (1997). Oxidized low-density lipoprotein stimulates endothelin-1 release and mRNA expression from rat mesangial cells. $\mathrm{J}$ Lab Clin Med 129:224-230.

Thomas EL, Grisham MB, and Jefferson MM (1986). Cytotoxicity of chloramines. Methods Enzymol 132:585-593.

Vissers MC, Day WA, and Winterbourn CC (1985). Neutrophils adherent to a nonphagocytosable surface (glomerular basement membrane) produce oxidants only at the site of attachment. Blood 66:161-166.

Vissers MC and Thomas C (1997). Hypochlorous acid disrupts the adhesive properties of subendothelial matrix. Free Radic Biol Med 23:401-411.

Winterbourn CC (1985). Comparative reactivities of various biological compounds with myeloperoxidase-hydrogen peroxide-chloride, and similarity of the oxidant to hypochlorite. Biochim Biophys Acta 840:204-210.

Woenckhaus C, Kaufmann A, Bussfeld D, Gemsa D, Sprenger H, and Gröne HJ (1998). Hypochlorite-modified LDL: Chemotactic potential and chemokine induction in human monocytes. Clin Immunol Immunopathol 86:27-33.

Yoshioka T and Ichikawa I (1989). Glomerular dysfunction induced by polymorphonuclear leukocyte-derived reactive oxygen species. Am J Physiol 257:F53-F59.

Zabe M, Feltzer RE, Malle E, Sattler W, and Dean WL (1999). Effects of hypochlorite-modified low-density and highdensity lipoproteins on intracellular $\mathrm{Ca}^{2+}$ and plasma membrane $\mathrm{Ca}^{2+}$-ATPase activity of human platelets. Cell Calcium 26:281-287. 